\title{
Levantamiento del Velo Societario en Colombia, Un análisis del artículo 43 de la Ley 1258 de $2008^{1}$
}

Marlon IVÁn Maldonado NarvÁeZ²

\section{RESUMEN}

El levantamiento del velo societario es una figura que cada vez ha venido cobrando mayor importancia a nivel mundial. Esto debido a la gran cantidad de situaciones que se presentan de abuso de los socios administradores a la personalidad jurídica societaria. Sin embargo, no obstante su importancia el tema no ha sido correctamente desarrollado, ya que no obstante tratarse de un procedimiento excepcional, no existen presupuestos legales para su aplicación. Por lo tanto usarlo como regla general para la reclamación de obligaciones laborales va en contravía de su naturaleza, afectando dicho sea de paso los intereses de los terceros afectados, debido a la complejidad para su ejercicio en lo relativo a la actividad probatoria.

Palabras Clave. Levantamiento del velo corporativo, abuso de la personalidad jurídica, protección de terceros, obligaciones laborales.

\section{ABSTRACT}

The lifting of the corporate veil is a figure that has become increasingly important worldwide. This is due to the large number of situations that arise

1 Este artículo es un avance de la investigación en curso titulada "Los medios de pago internacional desde el contexto regional", la cual es financiada por la Dirección de Investigación y Desarrollo de la Universidad Católica de Oriente, Rionegro, Antioquia (Colombia). Fecha de recepción: 10 de noviembre de 2016. Fecha de aceptación: 14 de diciembre de 2016. Para citar el artículo: Maldonado, M. "Levantamiento del Velo Societario en Colombia, Un análisis del artículo 43 de la Ley 1258 de 2008". Revist@ E-Mercatoria, vol. 15, №2, julio-diciembre, 2016. DOI: https://doi.org/10.18601/16923960.v15n2.04

2 Abogado, Magister en Derecho Empresarial de la Universidad Autónoma de Barcelona, Docente de las asignaturas Derecho Comercial y de Sociedades, Derecho Económico, Derecho Internacional y Contratos Internacionales de la Universidad de Boyacá. Email. mmaldonadon@hotmail.com 
from abuse of the managing partners to corporate legal personality. However, despite its importance, the issue has not been properly developed, since this is an exceptional procedure, there are no legal budgets for its implementation. Therefore, to use it as a rule for the claim of labor obligations is in wrong way of its nature, affecting in passing the interests of the affected third parties, due to the complexity for its exercise in relation to the probative activity.

Key Words. Lifting the corporate veil, abuse of legal personality, protection of third parties, labor obligations.

\section{INTRODUCCIÓN}

En los últimos años hemos sido testigos de cómo el exceso de liberalismo en el sector societario ha llevado a múltiples crisis económicas. Situaciones estas que ya no se circunscriben en un exclusividad a un solo Estado, sino que terminan por afectar a todo el mundo debido a la interdependencia económica facilitada por la globalización. No puede desconocerse la importancia de la flexibilización societaria para el crecimiento y desarrollo económico, pero tampoco se puede soslayar el hecho de que dicha flexibilización cuando se usa con fines no tan éticos han llevado a situaciones críticas.

Por tal sentido, con el tiempo el derecho y la economía se han venido fusionando como un sistema de pesos y contrapesos en los que se buscar dar un equilibrio al crecimiento económico sin que este afecte el perfeccionamiento de los derechos económicos en el Estado, y de su mano la realización de muchos derechos sociales dentro del Estado Social de Derecho.

Para cada creación dada en el sector económico que propenda por el desarrollo y crecimiento empresarial, debe darse igualmente una valoración de los costos de la afectación que pueda producirse al orden social. En los casos en que dicha tarea no se resuelve correctamente es el derecho quien a través de su poder coercitivo desarrolla los medios necesarios para facilitar el balance entre crecimiento y justicia.

El levantamiento del velo societario, o desestimación de la persona jurídica societaria, constituyen uno de esos remedios que a través del derecho se crean pensando en evitar que una medida desarrollada con un énfasis netamente económico, afecte la realización de otros intereses del Estado, en materia social y económica. Evitando de esta manera el caos y las consecuencias de éste, que son un mensaje negativo a los inversionistas respecto de un mal sistema jurídico.

Este tipo de medidas, al ser desarrolladas con excesiva cautela, su ejercicio no es una tarea fácil, ya que implican no solo un exhaustivo ejercicio probatorio para que el juez obtenga un pleno convencimiento. Con lo cual es dado afirmar que si bien se trata de una medida excepcional, su ejercicio es complicado para poder llegar a demostrar el abuso de la personalidad jurídica. 
Por lo cual, utilizar el levantamiento del velo societario como medida para reclamar el pago de prestaciones laborales por parte de los trabajadores, como regla general dentro de un modelo societario establecido en el Estado, se constituye en un mensaje en la vía opuesta para la que fue creada esta excepción, y al final termina más por generar comportamientos irresponsables de parte de los administradores societarios y de las mayorías controlantes.

\section{EL LEVANTAMIENTO DEL VELO}

Dentro de la evolución histórica del derecho societario, es posible apreciar como en un momento determinado el liberalismo económico se impuso sobre el mercantilismo propiamente dicho. No obstante estamos de acuerdo con Perdices (1994), en que dicha imposición no fue resultado de la victoria de unos ideales políticos o filosóficos de unos precursores de tal liberalidad, que afecta al sector societario, sino más bien de una situación de necesidad en la que se encontraron los Estados, incapaces de generar mayores recursos de rentas para su funcionamiento.

Aspecto este que se corresponde con toda facilidad con el pensamiento de los economistas clásicos en la búsqueda exclusiva del crecimiento económico. Lo cual es a la postre la búsqueda de la eficiencia económica (Méndez 1994), aunque ello también puede suponer la afectación de derechos de la comunidad en general, que igualmente pueden tener un coste económico alto para cualquier Estado y para la sociedad en general.

Tomando lo anterior como punto de partida, se han ido desarrollando las diferentes teorías asociadas a la empresa, las cuales plantean un modelo utópico de comportamiento económico, en el cual no se analiza la conducta de la misma (Bueno, Cruz y Durán, 1986). No obstante la historia ha sido testigo fiel de cuantos casos de quiebras y de crisis económicas se han dado en el planeta, debido a malas administraciones, a la asunción de riesgos innecesarios, al abuso de la personalidad jurídica como tal. El problema radica en que la actualidad la economía estatal y global están cada vez más interconectadas y cualquier fallo por pequeño que parezca puede terminar por afectar no solo la libre y sana competencia empresarial sino también la economía en general.

Uno de los principales contrapesos a este tipo de situaciones, facilitados por la limitación de la responsabilidad de las personas dentro de una sociedad comercial, lo constituye el levantamiento del velo corporativo. Este es uno de los elementos que actualmente se considera más importante para poner freno a los abusos de la personalidad jurídica por parte de los administradores societarios, tomando como punto de partida que, si la persona jurídica goza de ciertos derechos, indudablemente tendrá también ciertas obligaciones (Pound, 2008).

Lo anterior supone que, así como la Sociedad es considerada una persona jurídica distinta de los socios, este principio también puede variar en la medida en que sea necesario el levantamiento del velo para lograr la protección de los 
acreedores sociales que hayan resultado afectados por una conducta abusiva de la sociedad (Grantham, 1998).

Ante un escenario como el señalado surge esta excepción del levantamiento del velo corporativo. Como se anotó, se trata de una excepción, teniendo en cuenta que la regla general la constituye la limitación de la responsabilidad, e ir en contravía de la misma admite afectar el correcto funcionamiento de la economía, ya que se constituye en un mensaje negativo a muchos inversionistas, que puede preferir optar por no invertir en materia societaria, o simplemente un fomento a la ilegalidad. Empero en la actualidad, dicha excepción consideramos debe ser entendida como un elemento más dentro de las leyes del equilibrio económico-empresarial. (Bueno, Cruz y Durán, 1986)

El levantamiento del velo como tal consiste en el desconocimiento de la protección que brinda la limitación de la responsabilidad societaria. Una vez permeado el velo societario, los socios-administradores entrarán a responder de manera solidaria e ilimitada por los daños que se hayan podido ocasionar a terceros.

Esta teoría que tiene su fundamento principal en la buena fe negocial y el no fraude a la ley, surge en los Estados Unidos como Disregard of legal entity" la cual de acuerdo con Hurtado (2000) es posible situarla por primera vez en el caso Bank of the United States $v$ Deveaux, 1809, en la cual el juez que conoció de la misma sentenció que no obstante la parte involucrada en el proceso fuera una persona jurídica, en dicho caso debían responder como tal las personas naturales que la componían.

Posteriormente a esta sentencia, en otro caso muy famoso en Inglaterra, Salomon v Salomon y Co Ltd, 1897, la Cámara de los Lores revocó un fallo que en primera y segunda instancia había sido dado a favor del levantamiento del velo, alegando que la persona jurídica era hermética y que como tal no había manera de permearla. Si bien nos apartamos de la postura asumida por la Cámara de los Lores en el citado caso, el mismo sirve para mostrar como el levantamiento del velo es una figura que opera únicamente de manera excepcional.

En todo caso, el levantamiento del velo societario lo que busca es frenar el abuso del derecho y el fraude a ley. Aunque, al tratarse de una medida excepcional que queda a criterio del juez, la misma permite que diferentes situaciones puedan ser ventiladas bajo su seno $;$ no obstante, el exceso de discrecionalidad también puede resultar nocivo, ya que como se anotó queda únicamente conforme a la valoración que el juez haga del acervo probatorio a su disposición.

\section{FUNCIÓN ECONÓMICA}

Ya que la economía tiene un ámbito de aplicación tan amplio, puede decirse que la misma ha favorecido el desarrollo de muchas actividades para el desarrollo social. Empero, dada su amplitud, esto ha degenerado en una falta de especialización, por lo cual es el derecho en el que en últimas debe corresponder 
con la búsqueda de salidas a situaciones que puedan poner en riesgo intereses particulares y colectivos (Cabieses, 2012).

Si el derecho concursal tiene su fundamento en la necesidad de la protección de la empresa y el crédito pensando en que la sociedad pueda seguir funcionando, el levantamiento del velo corporativo tiene su fundamento en la protección a los acreedores sociales en aquellos casos, que por una administración en abuso de la personalidad jurídica se llega a una situación de insolvencia.

Así si bien se ha afirmado que la persona jurídica es distinta de los socios que la componen, en la economía se espera que dicha separación mejore la eficiencia, y en el derecho se espera que no haya una transgresión a la misma (Macey, 2014), a efectos de no tener que acudir a los remedios legales para normalizarla.

Debe existir correspondencia entonces entre la liberalidad del mercado y la protección jurídica a los inversionistas, en la medida en que está demostrado en que los Estados con menor protección a la economía en general se encuentran en una situación de subdesarrollo de sus mercados financieros, frente a otros Estados que paralelo al otorgamiento de ciertas libertades también establecen correctos controles (La Porta, López de Solanes, Schleifer, y Vishny, 1997).

En tal sentido promover la consecución de la política económica del Estado, evitar el fraude de parte de los socios, como consecuencia del mantenimiento del orden económico, y promover los procesos concursales de una manera equilibrada, sin la aparente existencia de favoritismos, se establecen en términos económicos, como los elementos fundantes del levantamiento del velo (Macey y Mitts, 2014).

\section{EL ABUSO DE LA PERSONALIDAD JURÍDICA}

Puede decirse en primera instancia que el abuso de la personalidad jurídica constituye un nuevo supuesto dentro del abanico de situaciones que se enmarcan dentro de la teoría general del abuso del derecho (Calaza, 2005). En unidad de criterio, es importante anotar que la misma Constitución Política de Colombia establece en su artículo 95, numeral 1, relativo a los deberes y obligaciones de las personas en el territorio nacional, que todas las personas están obligadas a respetar los derechos ajenos y no abusar de los propios. Norma que es aplicable a las personas jurídicas, y que en el caso concreto sirve para observar como el ordenamiento jurídico colombiano está pensado desde sus propios fundamentos filosóficos en la prohibición de cualquier conducta que vaya en dicha dirección.

Por tal razón es válido referenciar el artículo 830 del Código de Comercio, que establece que quien abuse del derecho estará obligado a indemnizar los perjuicios que cause. Tal artículo que es coherente con el marco constitucional, responde igualmente al hecho de que toda norma jurídica se refiere a la actividad de una persona frente a otra, entre las que surge una relación como 
sujetos activo y pasivo, a partir de la cual surge la facultad de exigir todo aquello que la ley concede al sujeto pasivo en virtud del inadecuado accionar del sujeto activo (Cuentas, 1997).

En este mismo sentido la Corte Constitucional señaló en Sentencia T-511 de 1993, que se abusa del derecho cuando su titular hace un uso inapropiado e irrazonable a la luz de su contenido esencial y de sus fines; el cual se patentiza aún más en el caso de que injustificadamente afecte otros derechos, desbordando sus propios límites. Esta sentencia es importante para el tema de estudio, ya que la misma sirve para aclarar que no basta con el abuso del derecho, sino que además se cause un daño injustificado a terceros.

Pudiéndose agregar el hecho de que en materia societaria la persona jurídica, se encuentra en una posición dominante frente a los terceros (Corte Constitucional de Colombia, Sentencia T-852 de 2010); afirmación que entendemos no debe limitarse únicamente a su participación o al volumen de la cuota de mercado que el ente posea, sino desde la óptica de la información de la sociedad, especialmente a nivel interno, en cuanto a su situación financiera y contable.

Las personas jurídicas, al igual que las personas naturales podrán hacer todo aquello que les sea permitido dentro de los límites del bien común. Es decir, sin abusar de su derecho o sin causar perjuicio al derecho del otro. Aunque a diferencia de las personas naturales, este concepto se complejiza en la medida en que dentro de la persona jurídica se albergan múltiples voluntades, que cuando llevan a la persona jurídica a un fin diferente para el cual se creó derivan en el abuso.

La personalidad jurídica propende por la creación de un orden, cuya existencia se justifica en la medida en que sirve como mecanismo para la movilización de capitales y otros fines de colaboración al Estado (Etcheverry, 1997). $\mathrm{Al}$ apartarse de dicho norte entonces nos encontramos ante la presencia de una situación que pone en peligro el equilibrio económico y social en que se desarrolla la persona jurídica, y que al ser digna de reproche debe aparejar una sanción (Rodríguez-Arias, 1955)

Es una verdad aceptada que es básicamente la separación de capitales entre la persona jurídica y las personas que la componen la que facilita este tipo de situaciones de abuso de la personalidad jurídica. Por lo tanto dentro de la figura del levantamiento del velo societario, en primera instancia lo que ha de reclamarse es el abuso del derecho. El cual si bien en primera instancia parece ser coherente con el ordenamiento jurídico en el que se desarrolla la sociedad, en el fondo oculta un comportamiento vulnerador del espíritu de la norma, con lo que adopta los visos de ilicitud que se reclaman, que afectan el equilibrio y la eficiencia del mercado, y que por tanto deben ser objeto de sanción. 


\section{PRESUPUESTOS MÁS COMUNES QUE DAN LUGAR AL LEVANTAMIENTO}

Es válido iniciar este apartado aclarando que la persona jurídica, de acuerdo con el ordenamiento jurídico vigente, debe obligatoriamente ser considerada un sujeto de derecho diferente al de las personas que la conforman; y que esta obligación no varía siempre que no exista un motivo, razonablemente válido para entender lo contrario (Galgano, 2009).

Como se ha visto hasta aquí, el levantamiento del velo societario es una medida excepcional frente a la limitación de la responsabilidad de los socios. Este aspecto, constituye una de las principales dificultades al momento de tratar de establecer cuáles serían los presupuestos objetivos que darían lugar al desconocimiento de la personalidad jurídica frente a los socios que hayan causado el daño.

Un común denominador existente entre los diferentes Estados que reconocen esta figura es la inexistencia de una norma que, enuncie o al menos oriente los casos en los que se habría de proceder a la aplicación de la misma. Por lo tanto, los mismos quedan sometidos a la valoración que un juez haga de las pruebas y demás elementos de juicio que se hagan valer dentro del proceso (Olavarría, 1970).

Sin embargo, la doctrina ha venido reconociendo unos elementos que son los que más comúnmente se presentan en este tipo de casos, y que se encuentran relacionados todos ellos con un comportamiento incorrecto de los sociosadministradores, el cual guarda un nexo causal con el daño que se ocasiona.

Es preciso aclarar que si bien es posible entender el fraude a los acreedores como un presupuesto objetivo que da lugar al levantamiento del velo, entendemos que en cada uno de los siguientes presupuestos que a continuación se enunciarán se encuentra implícito el fraude, como un modo de abuso de la personalidad jurídica y por el que deben responsabilizarse los socios que hayan dado lugar a dicha situación.

\section{Operaciones CON EL SOCIO CONTROLADOR}

Este presupuesto se presenta cuando constantemente la sociedad realiza operaciones con el socio controlante (Jaramillo, 2011). En este caso la sociedad se constituye más en un medio para la búsqueda de los objetivos de una o varias personas que tienen el control de la sociedad y no en la búsqueda de un fin social propiamente dicho.

Lo que se busca en este caso por parte del operador judicial es la verificación de si los planes de contratación de la sociedad, sus movimientos en general responden a una evaluación objetiva que permita maximizar los valores societarios, o si por el contrario reflejan un conflicto de intereses entre la sociedad y el socio (Macey, 2014). 


\section{ViOLACIÓN DE FORMALIDADES}

En este caso se trata de la realización de conductas que van en contra de lo requerimientos legales para la correcta existencia societaria, así como de los requerimientos previstos estatutariamente.

\section{CONFUSIÓN PATRIMONIAL}

Este caso que también es bastante común, se da cuando en la sociedad no se distinguen con claridad los activos sociales y el patrimonio personal de los socios (Jaramillo 2011); haciendo claridad que dicha confusión debe predicarse especialmente del o de los socios controladores de la sociedad, sin una obvia separación patrimonial y de intereses $(\mathrm{Oh}, 2013)$.

\section{LA SITUACIÓN DEL LEVANTAMIENTO DEL VELO SOCIETARIO EN COLOMBIA: ANÁLISIS DEL ARTÍCULO 42}

La Constitución Política Colombiana establece en su artículo 333 que la actividad económica y la iniciativa privada son libres dentro de los límites del bien común. Este apartado supone que si bien en Colombia se acogen postulados vanguardistas en materia societaria, su correcto desarrollo debe darse dentro de los límites del ordenamiento jurídico, de tal manera que no se afecte a terceros o la economía en general.

Tal como lo anota Arrubla Paucar (2010), si bien la figura es de origen norteamericano, su aplicación en Colombia no se da como resultado de una analogía jurisprudencial, sino con base en la regulación que ya se anotó sobre el abuso del derecho, citado en el artículo 830 del Código de Comercio, y por tanto su consecuencia inmediata.

Esta figura en Colombia es también conocida como Desestimación de la Personalidad Jurídica; no obstante su reconocimiento no existe una norma específica que reconozca en qué casos habrá de darse el levantamiento del velo societario. Si bien en algunos casos como el previsto en el artículo 42 de la Ley 1258 de 2008 se hace referencia al levantamiento del velo, ${ }^{3}$ dicho artículo no específica a concreción que situaciones podrán encuadrarse dentro del mismo.

3 Debe anotarse que tal norma no es la única que prevé dicha situación; también es posible enunciar el Código de Comercio en sus artículos 105 y 135; la Ley 1116 de 2006 en sus artículos 49, 61 y 82, entre otras.

Especial caso creemos que es el previsto en la ley 190 de 1995, sobre la preservación de la moralidad de la administración pública, también prevé en su artículo 44 un caso en el que habrá lugar a levantamiento del velo corporativo, como mecanismo para disminuir la corrupción en el país. No obstante dicho artículo hace referencia que dicha medida, que es potestativa del juez, lo hace únicamente, como lo dice la norma para saber quién 
Puede decirse que esta ausencia de criterios, o de conocimiento sobre la materia generaron en un ejercicio errático de dicha figura, con lo que es fácil de concluir que tal como lo estima el citado artículo, se termina por crear una pseudo-jurisdicción societaria, en cabeza de la Superintendencia de Sociedades; la cual es coherente con el artículo 24, numeral 5, literal d) del Código General del Proceso. Aspecto que entendemos positivo en atención al principio de especialización, aunque ello no suponga que los pronunciamientos que al respecto se puedan presentar no estén protegidos de ser atacados por vía de nulidad y restablecimiento.

En general, respetando el hecho de que el levantamiento del velo societario es una situación excepcional, la misma Corte Constitucional de Colombia reconoció en Sentencia C-510 de 1997, que no se trata de una situación de responsabilidad objetiva, sino una presunción juris tantum, la cual admite prueba en contrario en el sentido de aclarar que no ha sido la administración societaria la responsable de la situación económica que enfrenta la sociedad.

No obstante lo anotado en dicha sentencia, existen otros dos pronunciamientos muy similares entre sí (Sentencia SU-1023 de 2001 y SU-636 de 2003), que podríamos llamar como no tan afortunados en los que se ordena el levantamiento del velo de dos sociedades matrices, en los que se ordena que éstas deben responder por el pasivo pensional de sus filiales. Decimos que no son tan afortunadas, ya que no puede presumirse obligatoriamente que siempre que una sociedad sea filial y exista una matriz, toda la responsabilidad debe recaer sobre la matriz (Gaertner, 1989).

El citado artículo 42 de la Ley 1258 de 2008, solo tendrá operatividad en los casos en que se utilice la sociedad en fraude o perjuicio de terceros. A una lectura rápida de la norma, puede entenderse como positivo, sin embargo hay que anotar que la excepción solo opera en consonancia con la situación prevista en el artículo 1 de la citada ley respecto de la no responsabilidad por las obligaciones laborales que se causen.

Al respecto, la Corte Constitucional anotó en Sentencia C-090 de 2014, que

"no constituye una desprotección de los derechos del trabajador ni un incumplimiento de las disposiciones constitucionales que amparan el trabajo y la dignidad del trabajador, cuando quiera que existen mecanismos jurídicos para la defensa de los mismos, al tiempo que la separación patrimonial cumple el propósito constitucional de incentivar la creación de empresa y el desarrollo económico del país."

se beneficia con un acto corrupto, o para hacerlo responsable posteriormente obligando a que pague por el daño causado.

Puede igualmente citarse en este punto el parágrafo único del artículo 71 de la Ley 222 de 1995, el cual si bien no fue derogado directamente por la Ley 1258 de 2008, en la actualidad ya no es de aplicación, ante la imposibilidad de crear sociedades unipersonales. Dicho parágrafo también hacía referencia a la posibilidad de que el socio que hubiese usado la sociedad en fraude de ley o perjuicio a terceros, respondería por los perjuicios causados. 
Es dado afirmar que el levantamiento del velo societario en Colombia puede estar siendo objeto de un trato diferente al de la naturaleza con la que surgió como teoría. Ya que lo correcto es que en primera instancia la protección de los trabajadores sea legal, como derecho constitucional y no a ruego como se ha previsto en la norma en comento.

Lo que se aprecia es que el legislador dejó las obligaciones laborales sujetas a un procedimiento que como se anotó es excepcional y que, al no existir unos presupuestos específicos para la reclamación, el trabajador se encuentra sujeto a la subjetividad del funcionario que conozca del caso, por lo que además de impredecible puede decirse que es hasta aleatorio conseguir el levantamiento del velo (Macey y Mitts, 2014). Aspecto que se empeora, si se tiene en cuenta que es el demandante quien tiene la carga de probar que efectivamente se presentó o presentaron conductas abusivas de la personalidad jurídica, y que fueron estas las que llevaron a la situación de insolvencia; lo cual sumado a que en su mayoría se trata de información confidencial de la sociedad, son limitadas las opciones para demostrar lo desleal del comportamiento.

Tal situación empero, si se tiene en cuenta que de la redacción del artículo 1 y del 42 de la citada ley, es posible que los administradores eximan su responsabilidad, si demuestran que las actuaciones fueron adelantadas por el administrador societario, diferente a los socios, en apariencia dentro de los poderes conferidos, sin evidenciar que dicha conducta llevaría necesariamente a la situación que da origen al daño (Easterbrook y Fischel, 1996).

Estamos de acuerdo con Reyes (2012) en el sentido de que el legislador debió estudiar tanto más la situación del artículo 1 y ampliar la del 42, respecto de las consecuencias que las mismas podrían tener para los terceros acreedores de la sociedad, dentro de los que se encuentran los trabajadores, y en general todas aquellas acreencias que no cuenten con una garantía real dentro de la sociedad que avale su derecho.

\section{CONCLUSIONES}

Entendemos que el levantamiento del velo societario constituye una medida importante para poner freno a los abusos que se han venido presentando con ocasión del aprovechamiento de las ventajas dadas a la sociedad en lo referente a la autonomía de la personalidad jurídica y la limitación de la responsabilidad de los socios hasta el monto de sus aportes.

Así las cosas, cumple una muy importante función económica, toda vez que así como el Estado ha mostrado su interés en la protección de la empresa, lo cual constituye un estímulo a los inversionistas, es preciso también desarrollar mecanismos que sirva para controlar los abusos. Máxime cuando dicho control tiene asidero constitucional, al establecerse que en Colombia existe la libertad de empresa, pero con límites. 
Aunque, si bien excepcional, deben ser más claros los presupuestos objetivos por los que se aplica esta excepción a la regla general de la limitación de la responsabilidad, ya que la misma termina por generar inseguridad jurídica, al quedar dicha decisión en manos del juez, con lo cual será determinante el ejercicio probatorio que pueda realizarse. No obstante, no es fácil realizar correctamente el ejercicio probatorio, en especial cuando se trata de información contable o respecto de la motivación en la toma de decisiones, para demostrar que no se obró con la prudencia y buena fe requeridas.

Consideramos que en algunos casos, como el de las obligaciones laborales que se prevé en el artículo 1 de la Ley 1258 de 2008, que da lugar al levantamiento del velo, como lo anota el artículo 42 de la misma Ley, debería pensarse en la posibilidad de la inversión de la carga de la prueba. Si esta medida está pensada para servir como límite a los comportamientos poco éticos y fraudulentos que pueda cometer una sociedad, así mismo entendemos debe ser la sociedad, a través de sus administradores o los socios que ostenten las mayorías, la que pruebe que efectivamente su obrar no fue abusivo, sino coherente con la normatividad vigente y el funcionamiento del mercado.

Por lo tanto, consideramos que en la aplicación que se da al levantamiento del velo societario en el caso de la Ley 1258 de 2008 es distinta a las razones que le dieron su origen, ya que al tratarse de una medida excepcional y sin una regulación clara, la misma puede terminar por convertirse más en una talanquera para los terceros, que un mecanismo idóneo que permita la determinación de las responsabilidades a que haya lugar sin consideración de la limitación de la responsabilidad.

\section{REFERENCIAS}

AAVV ${ }_{\text {; }}$ Coporate personality in the 20th century, editors Ross Grantham y Charles Rickett, Editorial Hart Publishing, Oxford, 1998.

ARRUBLA PAUCAR, $J_{. ;}$"El levantamiento del velo corporativo en Colombia" en AAVV, Levantamiento del velo corporativo, panorama y perspectivas, el caso colombiano, Colección textos de jurisprudencia, Universidad del Rosario, Bogotá, 2010.

BUENO CAMPOS, E.; CRUZ ROCHE, I.; DURÁN HERRERA, J.; Economía de la Empresa, Análisis de las decisiones empresariales, Ediciones Pirámide, 8. a ed., Madrid, 1986.

CABIESES, Guillermo "El carácter interdisciplinario del derecho y la utilidad de la economía en su estudio" en AA.VV. Relaciones contemporáneas entre derecho y economía, Fernando Castilla y Juan Reyes, Coordinadores, Centro de Estudios de Economía y Derecho, Pontificia Universidad Javeriana, Grupo Bancolombia, Ibáñez, Bogotá, 2012. 
CALAZA LÓPEZ, M.; El proceso de impugnación de acuerdos de las sociedades anónimas y cooperativas, Centro de Estudios Ramón Areces, Madrid, 2005.

CUENTAS ORMACHEA, E.; "El abuso del derecho" en Revista de la Facultad de Derecho, Pontificia Universidad Católica del Perú, n. ${ }^{\circ}$ 51, 1997.

Colombia, Código de Comercio.

Colombia, Constitución Política.

Colombia, Corte Constitucional Sentencia T-511 de 1993.

Colombia, Corte Constitucional, Sentencia C-510 de 1997.

Colombia, Corte Constitucional, Sentencia T-852 de 2010.

Colombia, Corte Constitucional, Sentencia SU-1023 de 2001.

Colombia, Corte Constitucional, Sentencia SU-636 de 2003.

Colombia, Corte Constitucional, Sentencia C-090 de 2014.

Colombia, Ley 190 de 1995.

Colombia, Ley 222 de 1995.

Colombia, Ley 1116 de 2006.

Colombia, Ley 1258 de 2008.

EASTERBROOK, F; y FISCHEL, D.; The economic structure of corporate law, Editorial Harvard University Press, 1996.

ETCHEVERRY, R.; Derecho comercial y económico, formas jurídicas de la organización de la empresa, Editorial Astrea, Buenos Aires, 2005.

GAERTNER, M.; "Reverse piercing the corporate veil: should corporation owners have it both ways? En William \& Mary Law Review, Vol. 3, n. ${ }^{\circ}$ 3, 1989.

GALGANO, F.; "Dirección y coordinación de sociedades" en AA.VV., Los grupos societarios: Dirección y coordinación de sociedades, Colección de textos de jurisprudencia, Universidad del Rosario, Bogotá, 2009.

HURTADO COBLES, J., La doctrina del levantamiento del velo societario en España e Hispanoamericana, Editorial Atelier, Barcelona, 2008. 
JARAMILLO HERRERA, L.; "Desestimación de la personalidad jurídica en el derecho societario colombiano", en Revista CES DERECHO, Vol. 2, n. ${ }^{\circ}$ 2, 2011.

LA PORTA, R.; LÓPEZ DE SOLANES, F.; SCHLEIFER, A, y VISHNY, R.; "Legal determinants of external finance" en The Journal of Finance, vol. LII, n. ${ }^{\circ}$ 3, 1997.

MACEY, J.; "Finding in the morass: the three real justifications for piercing the corporate veil" en Cornell Law Review, Vol. 100:99, 2014.

MACEY, J.; y MITTS, J.; "Finding order in the morass: The three real justifications for piercing the corporate veil" en Cornell Law Review, Forthcoming: Yale Law \& Economics Research Paper, n. ${ }^{\circ} 448$.

MÉNDEZ IBISATE, F.; "El enfoque microeconómico: marginalismo y neoclásicos" en AA.VV. Ensayos sobre pensamiento económico, Jesús de la Iglesia, Coordinador, Ed. McGraw Hill, Madrid, 1994.

OH, P.; "Veil-Piercing Unbound" en Boston University Law Review, vols. 93-89.

OLAVARRÍA, J.; Manual de Derecho Comercial, tercera edición, Barcelona, 1970.

PERDICES BLAS, L.; "Entre el feudalismo y el liberalismo: diversidad de doctrinas y políticas "mercantiles" en Europa, en AA.VV. Ensayos sobre pensamiento económico, Jesús de la Iglesia, Coordinador, McGraw Hill, Madrid, 1994.

POUND, R.; Jurisprudence, Vol. 1. Parte 1. Jurisprudence, Ed. The Lawbook Exchange, Ltd. Unión, 6. ${ }^{\text {a }}$ ed., New Jersey, 2008.

REYES VILLAMIZAR, F.; Análisis Económico del Derecho Societario, Editorial Legis, 2. ed., Bogotá, 2013.

RODRÍGUEZ-ARIAS BUSTAMANTE, L.; "El abuso del derecho (Teoría de los actos antinormativos) en Revista de la Facultad de Derecho México, UNAM, 1955. 